\title{
Determinants of Compliance with Standard Practices of Pesticide Use Among Cocoa Farmers in Southwestern Nigeria
}

\author{
Anthony Eghe Agbongiarhuoyi ${ }^{1 *)}$ and Ogbaraeno Pippy Fawole ${ }^{2)}$ \\ ${ }^{1)}$ Department of Economics and Extension, Cocoa Research Institute of Nigeria (CRIN) Ibadan, Nigeria \\ ${ }^{2)}$ Department of Agricultural Extension and Rural Development, University of Ibadan, Ibadan, Nigeria \\ ${ }^{*}$ Corresponding author: toniagbons@gmail.com \\ Received : 5 June 2020 / Accepted : 30 June 2020
}

\begin{abstract}
Cocoa production in Nigeria is limited due to pests and diseases. In an attempt to control these, farmers apply pesticides which leave chemical residue in cocoa beans. There are established standard practices to address the abuse in use of pesticides. However, there is dearth of information on factors that predispose cocoa farmers to comply with approved standard practices. Therefore, determinants of compliance with standard practices of pesticide use by cocoa farmers in Southwestern Nigeria were investigated. A three-stage sampling procedure was used to select respondents. Two cocoa producing States (Oyo and Ondo) were purposively selected. Two Local Government Areas (LGAs) known for cocoa production were selected from each state. Systematic random sampling was used to select $10 \%$ of registered farmers to give 354 respondents. Interview schedule was used to collect data on respondents' variables. Data were analysed using descriptive statistics and multiple regression at $\alpha 0.05$. Most farmers were male $(70.3 \%)$ and had secondary education $(31.9 \%)$. Respondents' age and farming experience were 58.0 and 27.0 years, respectively. Farmers' yield and annual income were 0.449 tonnes obtained from an average of 6.25 ha cocoa farm size and

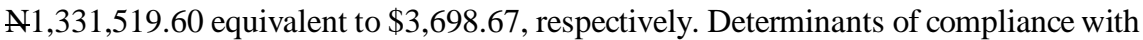
standard practices of pesticides use for both dosage and procedure were determined by age $(\beta=-0.20)$, income $(\beta=0.15)$, exposure to information $(\beta=0.36)$, constraints $(\beta=-0.27)$ and accessibility to approved pesticides $(\beta=-0.11)$. Exposure of farmers to information and realising more money motivates them to purchase approved pesticides that will aid compliance with standard practices. As age of farmer increases, the ability to comply will be limited. A farmer who is constraint with poor access to recommended pesticides will go for unapproved types which are against compliance. Concerted efforts should be put in place by relevant bodies to ensure sustainable income, information access for respondents in order to adhere to recommended protocols and enhanced cocoa yield.
\end{abstract}

Keywords: Practice compliance, dosage compliance, cocoa farmers, pesticide use

\section{INTRODUCTION}

Cocoa (Theobroma cacao L.) is a leading commodity crop in West Africa with over $70 \%$ of world cocoa production cultivated in the region. West Africa supplies $90 \%$ of cocoa required by European cocoa industry
(Crozier, 2013). Nigeria is a notable producer of cocoa beans in the world with Cote d'Ivoire being the highest. Other important producers are Ghana, Ecuador, Cameroon and Indonesia contributing to the enterprise (ICCO, 2020). In Nigeria, cocoa is widely grown by small-scale farmers in 14 States 
with a greater proportion from the South West (Adeniyi et al., 2014).

Globally, around 50 million people depend on cocoa for their livelihoods, while governments in producing countries rely on earnings from cocoa to finance economic and social development programmes (Fairtrade, 2016). Cocoa is the main agricultural export in Nigeria producing annually $300,000-350,000$ tonnes. Nigeria exports about $96 \%$ of its cocoa beans per year (Pedabo, 2013). The country's production is dependent on pesticides to attain acceptable levels of crop production. Cocoa plays a significant socio-economic role in Nigeria. It accounts for almost $2 \%$ of Nigeria's export earnings. It is a major source of foreign exchange for the country. Cocoa export contributed over $\mathrm{N} 103$ billion (\$338.17) to Nigerian economy in 2018 (Okunade, 2019). The crop serves as the single largest non-oil foreign exchange income earner contributing significantly to the nation's Gross Domestic Product (GDP). It provides employment for over 200,000 households in areas of the Nigeria that grow the crop (Popoola et al., 2015). Cocoa is used in the production of cocoa powder, chocolate, beverages, wine, bread, butter and other products.

For the sustainable production of these cocoa products, it is important to ensure compliance of farmers with approved pesticides application practices to control insect pests and diseases. Compliance is beneficial not only for consumers concerned with the food safety of the end product but is also beneficial to the health and wellbeing of producers and other stakeholders in the supply chain. Compliance helps to safe guard a sustainable supply of cocoa beans, income and improved quality for cocoa producing communities and the country as a whole. Annually, approximately 2 million tonnes of pesticides across the globe are utilized, out of which $47.5 \%$ are herbicides, $29.5 \%$ are insecticides,
$17.5 \%$ are fungicides and $5.5 \%$ are other pesticides (De et al., 2014). It has been estimated that by the year 2020, the global pesticide usage will increase up to 3.5 million tonnes (Zhang, 2018). Compliance with standard pesticides protocol helps to reduce the possibility of exceeding the Maximum Residue Limits (MRLs) of $0.01 \mathrm{mg} / \mathrm{kg}$ permitted for cocoa production (Bateman, 2015). The MRLs are the maximum concentration of pesticide residue (expressed as $\mathrm{mg} / \mathrm{kg}$ of residue to food/animal feed) likely to occur in or on food and feed after the use of pesticides according to Good Agricultural Practices (GAP).

The European Union (EU) observed traces of chemical residues in the cocoa beans exported to consuming countries (Okoffo et al., 2016). It has become a major concern in the international market due to its serious risk to the health of consumers of cocoa beans products. The importance of responsible pesticides use and compliance by farmers with approved pesticides is in line with Nigerian government effort in boosting cocoa production to meet increasing demand. However, its production is limited by so many factors some of which include effect of insect pest and diseases, poor quality beans, knowledge and attitude. Others include high cost of farm inputs such as fertilizers, pesticides, seeds, shortage of labour and so on (Idris et al., 2013; Cadoni, 2013). The issue of pesticide residue resulting from pesticides application is a major concern to consuming countries. It compromises cocoa bean quality leading to health problems and rejection of bean in the international market.

Okoffo et al. (2016) reported that indiscriminate use of chemicals to spray diseased cocoa trees on farm can have unintended environmental consequences and quality issues. This suggests non-compliance to acceptable standards. Ibitayo (2011) reported that some farmers do not follow instructions on the 
pesticides label and use their own discretion in mixing and applying self-determined dosage to achieve quick results. Bateman (2015) reports that an assessment of the quality of cocoa beans imported into the EU included measurement of traces of substances that have been used on cocoa farms and this has been a serious issue to consumers. Studies regarding pesticides have become important in order to ensure the production of good quality cocoa beans, decrease pesticide risk and help to improve public health policies. Pesticides can provide useful control solutions if applied properly. They must be approved for use on the basis of GAP to increase productivity and quality in a manner that respects both the environment and health standards.

In order to stem this situation, the Cocoa Research Institute of Nigeria (CRIN) in line with international standard screened and recommended some pesticides which were approved by government for farmers' use in controlling insect pests and diseases associated with cocoa. These include fungicides: Copper (1) Oxide + Metalaxyl-M, Metalaxyl + Copper (1) Oxide, Copper Hydroxide, Mandipropamid + Mefenoxam and Pyraclostrobin + Dimethomorph; insecticides: Thiamethoxam, Acetamiprid + Cypermethrin, Thiacloprid + Deltamethrin and Imidacloprid; herbicides: Glyphosate (CRIN, 2019).

Non-compliance with approved chemicals to control insect pest and disease problems necessitated the European Cocoa Association (ECA) and EU to place a regulation on the irrational use of pesticides on cocoa trees. There is dearth of information on whether farmers comply or not with recommended practices. Therefore, the study was carried out to describe the personal characteristics of cocoa farmers and ascertain the factors determining compliance with standard practices (dosage, procedure) of pesticides use by cocoa farmers in Southwestern Nigeria in the study area.

\section{MATERIALS AND METHODS}

\section{Study Area}

The study was carried out in Oyo and Ondo States in the Southwestern Nigeria. Oyo State covers an area of 2.79 million hectares of land out of which 332,667 hectares can support cocoa production. The State has 41,447 ha currently under cultivation. Ondo state is the highest and leading cocoa producing state while Oyo States is a medium producer. There are 33 Local Government Areas (LGAs) in Oyo State, out of which 17 produce cocoa. Ondo State covers a land area of $14,793 \mathrm{~km}^{2}$. It has 326,000 ha suitable for cocoa production. The current area under cultivation is 149,687 ha (CRIN, 2008). Ondo State has 18 LGAs, out of which 14 produce cocoa. The target population of the study comprised small scale cocoa farmers from Oyo and Ondo States who were duly registered with Tree Crop Units in the State Ministries of Agriculture.

\section{Sampling Procedure}

A multi-stage sampling procedure was used in selecting the respondents for the study. The first stage involves purposive selection of two States (Oyo and Ondo) and two Local Governments Areas (LGAs) predominantly producing cocoa. The next stage was the random selection of respondents among the registered cocoa farmers in the selected local governments. In Oyo and Ondo States, the LGAs that were involved in large scale cocoa production were selected for the study. Two LGAs each were selected from the two States due to their high level of production. A systematic random sampling was used to select ten percent of the registered farmers from the States Ministry of Agriculture in each of the selected local government areas. This was done by simple random sampling technique 
based on the list of cocoa farmers. In Oyo State, out of the total number of registered farmers in Afijio and Oluyole LGAs, 26 and 20 were selected respectively. In Ondo State, out of the total number of registered farmers in Idanre and Akure South LGAs, 228 and 88 were selected respectively making a total of 362 which were proposed for the study but 354 were later used because some of the interview schedule instruments were not useful for analysis.

\section{Data Collection Methods}

Data were collected with the use of interview schedule from field survey of cocoa farmers. The instrument contains independent variables (personal characteristics): age, farming experience, number of years spent schooling, farm size and yield. Other variables investigated include estimated annual income, exposure to information, constraints, accessibility, knowledge, attitude and cocoa beans price of respondents. The dependent variable was compliance in terms of dosage and procedure with standard practices of pesticides use. Secondary data were also obtained from published and unpublished sources found in journals, books, proceedings and others materials. Table 1 describes the independent variables of the study.

The dependent variable of the study is compliance with standard practices of pesticides use on cocoa production. First, an approved guide on standard pesticides practices was used to know respondents that complied or not. The respondents were asked to tick the recommended pesticides they use out of the list provided. Those that indicated that they use a particular pesticide were further asked to indicate the dosage and procedure of use to spray cocoa trees. The information so obtained for each pesticide from each respondent on dosage and procedure were compared with the approved practice. Any deviation from the approved for dosage and procedure was considered by the researcher as non-compliance. A score of 0 was therefore assigned to noncompliance while a score of 1 was assigned to compliance. A compliance score for each of the respondent was computed based on the number of pesticides used. Compliance was computed in the form of percentage compliance, which is the proportion of the number of pesticide used to which respondents complied multiplied by 100 for both dosage and procedure.

Table 1. Measurement of independent variables of the study

\begin{tabular}{|c|c|c|}
\hline Variables & Description & Variable type/criteria \\
\hline Sex & Sex of farmers & Dummy: male $=1$, female $=2$ \\
\hline Marital status & Marital situation & $\begin{array}{l}\text { Categorical variable: } \text { married }=1 \text {, single }=2 \text {, } \\
\text { divorced }=3 \text {, widowed }=4\end{array}$ \\
\hline Age & Age of farmers & Continuous variable \\
\hline Cocoa farm size & Total cocoa farm size in ha & Continuous variable \\
\hline Price of cocoa beans & Price of cocoa beans in Naira & Continuous variable \\
\hline Estimated annual income & $\begin{array}{l}\text { Estimated annual income from cocoa beans } \\
\text { in Naira }\end{array}$ & Continuous variable \\
\hline Years of experience & Total number of farming experience in years & Continuous variable \\
\hline Cocoa yield last season & Total number of bags $/ \mathrm{kg}$ cocoa beans & Continuous variable \\
\hline $\begin{array}{l}\text { Number of years spent } \\
\text { schooling }\end{array}$ & Total number of years spent schooling & Continuous variable \\
\hline Exposure to information & Sources of information with score value & Never $=0$, occasionally $=1$, often $=2$ \\
\hline Constraints & Farmers' constraints with score value & $\begin{array}{l}\text { Categorical variable: } \text { major }=3, \text { minor }=2 \text {, } \\
\text { not a constraint }=1\end{array}$ \\
\hline Accessibility & Access to approved pesticides & Dummy: have access $=1$, no access $=2$ \\
\hline Knowledge attitude & $\begin{array}{l}\text { Knowledge of farmers on pesticides use with } \\
\text { scored value attitude of farmers to } \\
\text { pesticides use (Use of attitudinal questions } \\
\text { with scored value) }\end{array}$ & $\begin{array}{l}\text { Dummy: } \text { Correct }=1, \text { incorrect }=2, \text { strongly } \\
\text { agree }=5, \text { agree }=4, \text { undecided }=3, \\
\text { disagree }=2, \text { strongly disagree }=1\end{array}$ \\
\hline
\end{tabular}


Table 2. Approved guide on standard practices for recommended pesticides dosage and procedure

\begin{tabular}{|c|c|c|c|}
\hline Pesticides & Dosage & Procedure & Target pests/disease/weed \\
\hline \multicolumn{4}{|l|}{ Fungicides } \\
\hline $\begin{array}{l}\text { 1. Ridomil Gold } \\
\text { Plus WP } 66\end{array}$ & $\begin{array}{l}\text { Dissolve } 50 \mathrm{~g} / 15 \mathrm{~L} \text { of water in } \\
\text { a knapsack sprayer }\end{array}$ & $\begin{array}{l}\text { First add half of the water inside knapsack } \\
\text { sprayer and put chemical. Cover and shake. } \\
\text { Then, add the remaining, mix well, cover } \\
\text { and shake again before spraying. } \\
\text { The fungi cides should be sprayed } \\
\text { every } 21 \text { days interval }\end{array}$ & Black pod \\
\hline 2. Funguran ${ }^{-\mathrm{OH}}$ & $\begin{array}{l}\text { Dissolve } 60 \mathrm{~g} / 15 \mathrm{~L} \text { of water } \\
\text { in knapsack sprayer }\end{array}$ & Same procedure is applied & Black pod \\
\hline 3. Ultimax plus & $\begin{array}{l}\text { Dissolve } 50 \mathrm{~g} / 15 \mathrm{~L} \text { of water in } \\
\text { a knapsack sprayer }\end{array}$ & Same procedure is applied & Black pod \\
\hline 4. Champ DP & $\begin{array}{l}\text { Dissolve } 50 \mathrm{~g} / 15 \mathrm{~L} \text { of water in } \\
\text { a knapsack sprayer }\end{array}$ & Same procedure is applied & Black pod \\
\hline 5. Kocide 2000 & $\begin{array}{l}\text { Dissolve } 50 \mathrm{~g} / 15 \mathrm{~L} \text { of water in } \\
\text { a knapsack sprayer }\end{array}$ & Same procedure is applied & Black pod \\
\hline \multicolumn{4}{|l|}{ Insecticides } \\
\hline 6. Actara $25 \mathrm{WG}$ & $\begin{array}{l}\text { Dissolve } 6 \mathrm{~g} / 10 \mathrm{~L} \text { of water in } \\
\text { a knapsack sprayer }\end{array}$ & Same procedure is applied & Mirids \\
\hline 7. Esiom $150 \mathrm{SL}$ & $\begin{array}{l}\text { Dissolve } 8.33 \mathrm{~mL} / 10 \mathrm{~L} \text { of water } \\
\text { in knapsack sprayer }\end{array}$ & $\begin{array}{l}\text { The insecticides should be sprayed } \\
\text { every } 30-35 \text { days interval }\end{array}$ & Mirids \\
\hline $\begin{array}{l}\text { 8. Proteus } 170 \\
\text { O-TEC }\end{array}$ & $\begin{array}{l}\text { Dissolve } 27 \mathrm{~mL} / 10 \mathrm{~L} \text { of water in } \\
\text { knapsack sprayer }\end{array}$ & Same procedure is applied & Mirids \\
\hline \multicolumn{4}{|l|}{ Herbicides } \\
\hline 9. Clear weed & $\begin{array}{l}\text { Dissolve } 200 \mathrm{~mL} / 15 \mathrm{~L} \text { of water in } \\
\text { knapsack sprayer }\end{array}$ & Same procedure is applied & Weeds \\
\hline 10. Touch Down & Same dosage for 9 & $\begin{array}{l}\text { Same procedure is applied. The herbicides } \\
\text { should be sprayed every } 3 \text { months interval }\end{array}$ & Weeds \\
\hline 11. Round Up & Same dosage for 9 & Same procedure is applied & Weeds \\
\hline
\end{tabular}

The approved guide for recommended pesticides dosage and procedure from CRIN used for the study is shown in Table 2.

\section{Data Analysis and Analytical Tools}

Descriptive statistics (mean, frequency, percentage distribution) were used to analyse the independent variables. Multiple regression was used to determine the significant determinants contributions of the independent variables to the dependent variable. These were done by putting the independent variables into the regression equation in order to know those variables that affect compliance with pesticide use. The independent variables were used to test against the compliance score of the dependent variable. The level of significance was tested at $\mathrm{p}<0.05$.
The model is expressed as:

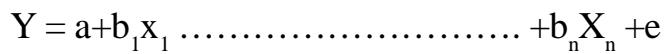

Where:

$\mathrm{Y}=$ Compliance with standard pesticides use on cocoa $(1=$ compliance, $0=$ Non- compliance $)$.

$=$ Constant term.

$b_{1}, b_{2} \ldots$ bn $=$ Regression coefficients.

$\begin{aligned} \mathrm{b}_{1}, \mathrm{~b}_{2} \ldots \mathrm{bn} & =\text { Regression } \\ \mathrm{e} & =\text { error term. }\end{aligned}$

$\mathrm{X}_{1}, \mathrm{X}_{2} \ldots \mathrm{X}_{\mathrm{n}}=$ Selected independent variables which include:

$\mathrm{X}_{1} \quad=$ Age of respondents (total age in years).

$\mathrm{X}_{2} \quad=$ Cocoa farm size in hectares

$\mathrm{X}_{3}=$ Price of cocoa beans (actual price of cocoa beans in Naira).

$\mathrm{X}_{4} \quad=$ Estimated annual income from cocoa beans (actual earnings).

$\mathrm{X}_{5} \quad=$ Years of experience in cocoa farming (total number).

$\mathrm{X}_{6} \quad=$ Cocoa yield (in $\mathrm{kg} / \mathrm{ha}$ )

$\mathrm{X}_{7} \quad=$ Number of years spent schooling.

$\mathrm{X}_{8} \quad=$ Exposure to information (score value).

$\mathrm{X}_{9} \quad=$ Constraints (score value)

$\mathrm{X}_{10} \quad=$ Accessibility to approved pesticides (score value).

$\begin{aligned} \mathrm{X}_{11}= & \text { Knowledge level of cocoa farmers on pesticides } \\ & \text { use (score value). }\end{aligned}$

$\begin{aligned} \mathrm{X}_{11}= & \text { Knowledge level of cocoa farmers on pesticides } \\ & \text { use (score value) }\end{aligned}$

$\mathrm{X}_{12}=$ Attitudinal disposition to cocoa pesticide use (score value). 


\section{RESULTS AND DISCUSSION}

\section{Personal Characteristics of Respondents}

The results in Table 3 show that $70.3 \%$ of the respondents were males while $29.7 \%$ were females. It indicates that men were more involved in cocoa production. This is similar to the study of Akintelu et al. (2019) which reported that men actively participated in cocoa production compared to the female cocoa farmers in Oyo State. Married people (77.1\%) were more involved in cocoa production than single $(5.7 \%)$, divorce $(4.2 \%)$ and widowed (13.0\%). It means that cocoa farming operation using pesticides were carried out by married men and women. This suggests availability of family labour for application of pesticides on cocoa trees.

The mean age of respondents was 58 years. It suggests that most of them were gradually aging and could be limited in carrying out production practices. For instance, an aging cocoa farmer carrying $15 \mathrm{~L}$ knapsack sprayer to spray cocoa tress in an acre of cocoa will find it difficult to effectively handle when compared to a youth. It implies that the farmers were getting old and this may affect their use and compliance with pesticides standard for cocoa production in the study areas. Conversely, youths who are more energetic people are less involved in cocoa production. This indicates that cocoa production is left in the hands of aged farmers that are not physically strong to carryout farming operations. It was reported by Iremiren (2011) that old people were more involved in cocoa production in Nigeria. Most cocoa farmers in villages are growing old and this could limit their farming activities. This is seen as a factor that will militate against government efforts to promote a tripling of cocoa production.
The educational status of respondents shows that more $(37.3 \%)$ had primary and $31.9 \%$ went to secondary school while $20.9 \%$ of respondents had no formal education. The least was tertiary having about $10 \%$. It means that majority had one form of education or the other which will likely help them to read pesticides labels before use which will assist in compliance to pesticides application. The respondents had varying farming experience. The bulk $(37 \%)$ of these respondents had 21-30 years of farming experience in cocoa farming. This was closely followed by $33.6 \%$ with farming experience of 11-20 years. Their mean farming experience was 27 years. These findings imply that the farmers had enough years of farming experience which could be an added advantage for adherence to standard practices of pesticides use. Years of experience have often contributed to the productivity of farmers since farmers with many years of experience are likely to be more skilled than those with lesser years of experience. A study conducted by Eze \& Olorunfemi (2010) revealed that most cocoa farmers had relevant length of farming experience in cocoa production activities. In terms of farm size, the result shows that $59.6 \%$ of respondents had 6-10 hectares (ha), $36 \%$ had less or equal to 5 ha and those who owned above 15 ha were only $0.6 \%$. The mean farm size was 6.25 ha. The implication of this is that cocoa farm size which was normally between 1-5 ha are gradually increasing. The expansion will suggest more use of pesticides on cocoa trees. Idris et al. (2013) supported this finding that the average farm size of 7.18 ha indicates that cocoa farmers were relatively medium scale producers.

The mean yield was $3,125 \mathrm{~kg}$ obtained from 6.25 ha cocoa farm size which translated to 0.499 tonnes/ha. This suggest that most respondents obtained a reasonable yield from their farms. Although reports may be conflicting, annual cocoa yields for Nigeria 
are generally estimated at an average of between 300,000 to 350,000 tonnes (Fairtrade, 2016). The average yield/ha of traditional cocoa variety is less than $450 \mathrm{~kg} / \mathrm{ha}$ while hybrids developed by CRIN produces 1.9 to 2.3 tonnes/ha (Agbongiarhuoyi et al., 2019). The result of the study however gave an increase above estimated yield due to good agricultural practices and increased farm sizes of farmers in the study area. The application of the right pesticide to control insect pest and diseases of cocoa will reduce infestation and enhance yield. The implication of this is that the use of pesticides will likely increase the yield of cocoa. This situation was also reported in Nepal by Bhandari (2014) that optimum use, correct method and right time of application of pesticides ensures increased crop production. This was reflected in the estimated income which earned respondents an average of $\$ 3,698$ during cocoa season. In Nigeria, cocoa farmers believe that if they do not apply insecticide and fungicide to control insect pest and disease attack, they will record poor yield. The reason for this is that blackpod disease is predominantly affecting cocoa trees and if not controlled, the damage in terms of annual crop loss is as high as $90 \%$ (Adeniyi, 2019).

The respondents realised over three thousand dollars estimated income from the sales of cocoa beans in the study area. Those who obtained less or equal to $\$ 1,388$ were $16.9 \%$. It means that majority of the respondents got some reasonable income from cocoa production before this study was conducted in 2017. The price of cocoa beans was quite good during this period and the pesticides used could have boosted production of respondents which could enhance compliance. This is an indication that high income will motivate farmers to purchase approved pesticides that will be used to control disease problems on cocoa. The findings of Ogunjimi \& Farinde (2012) supported the above results that cocoa farmers realised more income from their cocoa farms sprayed with chemicals which might be due to increase in price of cocoa in international market.

There is no significant contribution of the selected factors on compliance with standard practices of pesticide use by farmers. The contribution of the factors on compliance with standard practices of pesticide use in Table 4 is discussed for both procedure and dosage of approved pesticides used by farmers. The results show that compliance with standard practices of pesticide used by farmers was regressed with the independent variables in order to ascertain the determinants of compliance in the study area. These independent variables include age, cocoa farm size, price of cocoa beans, estimated annual income, years of experience, cocoa yield for previous season, number of years in school, exposure to information, constraints, accessibility, knowledge and attitude of respondents towards standard practices of cocoa pesticide use.

\section{Determinants of Respondents' Compliance}

The result in Table 4 gave an $\mathrm{R}$ square value of 0.285 meaning that variables in the regression model put together explain $28.5 \%$ variation of the contribution to the dependent variable. The result shows that compliance with both dosage and procedure of pesticide use by respondents was determined by exposure of farmers to information $(\beta=0.36)$, constraints $(\beta=-0.27)$, age $(\beta=-0.20)$, estimated annual income $(\beta=0.15)$ and accessibility $(\beta=-0.11)$. Exposure of farmers to information $(\beta=0.36)$ and estimated annual income $(\beta=0.15)$ contributed positively to compliance with standard practices. The implication is that for every unit increase in exposure to information and estimated income from cocoa, compliance with approved practices increase by 0.36 and 0.15 units. 
Table 3. Selected personal characteristics of respondents $\mathrm{N}=354$

\begin{tabular}{|c|c|c|c|}
\hline Variables & Frequency & Percentage & Mean \\
\hline \multicolumn{4}{|l|}{ Sex } \\
\hline Male & 249 & 70.3 & \\
\hline Female & 105 & 29.7 & \\
\hline \multicolumn{4}{|l|}{ Marital status } \\
\hline Married & 273 & 77.1 & \\
\hline Single & 20 & 5.7 & \\
\hline Divorced & 15 & 4.2 & \\
\hline Widowed & 46 & 13.0 & \\
\hline Age in years & & & 58.2 \\
\hline Less or equal to 30 & 7 & 2.0 & \\
\hline $31-40$ & 36 & 10.2 & \\
\hline $41-50$ & 77 & 21.8 & \\
\hline $51-60$ & 83 & 23.4 & \\
\hline $61-70$ & 97 & 27.4 & \\
\hline Above 70 & 54 & 15.2 & \\
\hline \multicolumn{4}{|l|}{ Educational status } \\
\hline No formal education & 74 & 20.9 & \\
\hline Primary & 132 & 37.3 & \\
\hline Secondary & 113 & 31.9 & \\
\hline Tertiary & 35 & 9.9 & \\
\hline Farming experience in years & & & 26.5 \\
\hline Less or equal to 10 & 17 & 4.8 & \\
\hline $11-20$ & 119 & 33.6 & \\
\hline $21-30$ & 131 & 37.0 & \\
\hline $31-40$ & 50 & 14.1 & \\
\hline $41-50$ & 29 & 8.20 & \\
\hline Above 50 & 8 & 2.30 & \\
\hline Cocoa farm size (ha) & & & 6.25 \\
\hline Less or equal to 5 & 126 & 35.6 & \\
\hline $6-10$ & 211 & 59.6 & \\
\hline $11-15$ & 15 & 4.2 & \\
\hline Above 15 & 2 & 13.0 & \\
\hline Yield of cocoa/ha & & & 0.499 tonnes \\
\hline Less or equal 1 tonne & 46 & 13.0 & \\
\hline 1-2tonnes & 90 & 25.4 & \\
\hline 2-3tonnes & 69 & 19.5 & \\
\hline 3-4 tonnes & 59 & 16.7 & \\
\hline 4-5tonnes & 39 & 11.0 & \\
\hline Above 5tonnes & 51 & 14.4 & \\
\hline Estimated annual income $(\mathbb{N})$ & & & $(\mathrm{N} 1,331,520)$ \\
\hline Less or equal 500,000 & 60 & 16.9 & $(\$ 3,699)$ \\
\hline $501,000-1,000,000$ & 95 & 26.9 & \\
\hline $1,000,001-1,500,000$ & 68 & 19.2 & \\
\hline $1,501,000-2,000,000$ & 63 & 17.8 & \\
\hline Above $2,000,000$ & 68 & 19.2 & \\
\hline
\end{tabular}

Exposure of farmers to information and getting more money will motivate them to purchase approved pesticides that will aid compliance with standard practices. Also, as age of farmers increases, the ability to comply will be limited. A farmer that is constraint with poor access to recommended pesticides will go for unapproved types which are against compliance.
The result is in line with Ogunjimi \& Farinde (2012) who reported that most cocoa farmers were exposed to information on chemical usage from extension agents, fellow farmers and sales agent. They added that cocoa farmers having more income were due to increase in price of cocoa in international market. 
Table 4. Contributions of variables in the regression equation to both dosage and procedure compliance with standard practices of pesticide use on cocoa trees

\begin{tabular}{|c|c|c|c|}
\hline \multirow{2}{*}{ Determining factors } & \multicolumn{3}{|c|}{ Both dosage and procedure } \\
\hline & Beta & $\mathrm{t}$ & Sig. \\
\hline (Constant) & & 9.525 & 0.000 \\
\hline Age & -0.203 & -3.044 & $0.003 *$ \\
\hline Cocoa farm size & 0.071 & 1.080 & 0.281 \\
\hline Price of cocoa beans & -0.032 & -0.689 & 0.492 \\
\hline Estimated annual income & 0.147 & 2.220 & $0.027 *$ \\
\hline Years of experience & 0.080 & 1.203 & 0.230 \\
\hline Cocoa yield last season & 0.048 & 0.944 & 0.346 \\
\hline Number of years spent schooling & 0.033 & 0.659 & 0.510 \\
\hline Exposure to information & 0.358 & 5.439 & $0.000 *$ \\
\hline Constraints & -0.271 & -4.485 & $0.000 *$ \\
\hline Accessibility & -0.111 & -1.996 & $0.047 *$ \\
\hline Knowledge & 0.005 & 0.087 & 0.931 \\
\hline Attitude & 0.011 & 0.207 & 0.836 \\
\hline
\end{tabular}

Variables such as constraints $(\beta=-0.27)$, age $(\beta=-0.20)$ and accessibility $(\beta=-0.11)$ contributed negatively to compliance with standard practices of pesticides use by farmers. It implies that for every unit increase in constraints, farmers' age and accessibility, compliance with standard practices decreases by $-0.27,-0.20$ and -0.11 units respectively. Idris et al. (2013) corroborated this result and reported that farmers who use pesticides for cocoa production encounter constraints of high cost of pesticides and non-availability in some cases. Other variables in Table 4 did not significantly influence compliance with standard practices of pesticide use.

\section{CONCLUSIONS}

Based on the findings of the study, the basic education of respondents assisted them in acquiring some knowledge about the use of pesticides in controlling cocoa insect pest and diseases. A reasonable number of respondents were growing old in age. This was found to reduce compliance with standard practices. Compliance with dosage and procedure was found to be low in the study area. The main factors determining respondents' compliance with standard practices of pesticides use in cocoa production for both dosage and procedure were determined by age, income, exposure to information, constraints and accessibility to approved pesticides.

\section{ACKNOWLEDGEMENTS}

Our sincere appreciation goes to God who in his infinite goodness made it possible to complete this task. Dr. Badaru I.O. and Dr. Thomas K.A. of Department of Agricultural Extension and Rural Development, University of Ibadan, Ibadan are appreciated for their valuable suggestions in improving the study. The management of Cocoa Research Institute of Nigeria (CRIN) Ibadan is also acknowledged for the time granted to undertake this research work.

\section{REFERENCES}

Adeniyi, D. (2019). Diversity of cacao pathogens and impact on yield and global production. p. 1-12. In: Theobroma cacao-Deploying Science for Sustainability of Global Cocoa Economy (P.O. Aikpokpodion, Ed.). Intech Open. 
Adeniyi, O.R. \& G.O. Ogunsola (2014). Cocoa production and related social-economic and climate factors: A case study of Ayedire local government area of Osun State, Nigeria. Agricultural Science, 2(4), 1-13.

Agbongiarhuoyi, A.E.; O.O. Oduwole \& C.O. Jayeola (2019). CRIN Developed Technologies Research Innovation Guide for Development. Cocoa Research Institute of Nigeria, Ibadan.

Akintelu, S.O.; L. Mele; V.O. Sobanke \& M. Adewunmi (2019). Adoption of some cocoa production technologies by cocoa farmers in Kogi State, Nigeria. Internatioal Journal of Agriculture Innovation, Technology and Globalisation, $1,31-43$.

Bateman, R. (2015). Pesticides Use in Cocoa: A Guide for Training Administrative and Research Staff. $3^{\text {rd }}$ Edition. International Cocoa Organization (ICCO). Westgate, London.

Bhandari, G. (2014). An overview of agrochemicals and their effects on environment in Nepal. Applied Ecology and Environmental Sciences, 2(2), 66-73.

Cadoni, P. (2013). Analysis of Incentives and Disincentives for Cocoa in Nigeria. Technical notes series, Monitoring African Food and Agricultural Policies Project. FAO, Rome.

CRIN (2008). Cocoa Production Survey Final Report 2007. Submitted to the National Cocoa Development Committee. Cocoa Research Institute of Nigeria, Ibadan.

CRIN (2019). List of Pesticides Currently Approved for Use on Cocoa Farms in Nigeria. (E.U. Asogwa, Ed.). Cocoa Research Institute of Nigeria. Ibadan.

Crozier, J. (2013). Assessing pesticide use in cocoa. Cocoa SPS Africa: Project Results and Dissemination Workshop Abidjan. Abijan, Côte d'Ivoire, 10-12th December 2013. CABI.
De, A.; R. Bose; A. Kumar \& S. Mozumdar (2014). Targeted Delivery of Pesticides Using Biodegradable Polymeric Nanoparticles. Springer, Berlin.

Eze, S.O. \& O.E. Olorunfemi (2010). Farmers' perception on cocoa production constraints in Akure South local government Area of Ondo State: Implications for political economies and food security in Nigeria. Nigerian Journal of Rural Sociology, 10(1), 35-45.

Fairtrade (2016). Fairtrade and Cocoa. Commodity briefing, Fairtrade Foundation, London.

Ibitayo, O. (2011). Agricultural pesticide contamination. Encyclopedia of Earth.

ICCO (2020). ICCO Quarterly Bulletin of Cocoa Statistics. Vol. XLVI, No. 1, Cocoa year (2019/2020). International Cocoa Organization on 6-03-2020.

Idris, A.; K. Rasaki; T. Folake \& B. Hakeem (2013). Analysis of pesticide use in cocoa production in Obafemi Owode Local Government Area of Ogun State, Nigeria. Journal of Biology, Agriculture and Healthcare, 3(6), 1-9.

Iremiren, G.O. (2011). Soil fertility and ageing cocoa farms in Nigeria. Paper Presented in World Cocoa Foundation. PartnershipMeetings, WCF.

Ogunjimi, S.I. \& A.J. Farinde (2012). Farmers' knowledge level of precautionary measures in agro-chemicals usage on cocoa Production in Osun and Edo States, Nigeria International Journal of Agriculture and Forestry, 2, 186-194.

Okoffo, E.D.; M. Mensah \& B.Y. Fosu-Mensah, (2016). Pesticides exposure and the use of personal protective equipment by cocoa farmers in Ghana. Environmental Systems Research, 5(17) (on line).

Okunade, T. (2019). Nigeria earned over N103 billion from cocoa commodity export in the year 2018. Nairametrics. Logos, Negeria. 
Pedabo (2013). Doing Business Guide Nigeria. $1^{\text {st }}$ edition. Morison International. Pedabo Associated.

Popoola, O.A.; G.O. Ogunsola \& K.K. Salman (2015). Technical efficiency of cocoa production in Southwest Nigeria. International Journal of Agricultural and Food Research, 4(4), 1-14.
Zhang, W. (2018). Global pesticide use: Profile, trend, cost/benefit and more. Proceeding International Academy of Ecology Environmental Science, 8(1), 1-27.

$* * 0 * *$ 